\title{
Rip Currents Have Least Friction
}

\author{
Kern E. Kenyon \\ 4632 North Lane, Del Mar, USA
}

Correspondence to: Kern E. Kenyon, kernken@aol.com

Keywords: Rip Currents, Least Friction

Received: April 10, $2020 \quad$ Accepted: May 12, $2020 \quad$ Published: May 15, 2020

Copyright $\odot 2020$ by author(s) and Scientific Research Publishing Inc.

This work is licensed under the Creative Commons Attribution International License (CC BY 4.0).

http://creativecommons.org/licenses/by/4.0/

\section{(c) (i) Open Access}

\section{ABSTRACT}

Surface gravity waves continually come to the beach but rarely go back to sea. They bring excess mass to shore which must be returned offshore. Rip currents do that job because there is less overall friction in the nearshore region than there is in the only other imagined circulation, a two-layer scheme, which has in fact never been seen. An argument is presented to support this proposal. If correct, rip currents join a group of geophysical flow phenomena that persist, probably because there is zero friction associated with them, which include surface gravity waves, tornadoes and hurricanes, individually promoted recently.

\section{INTRODUCTION}

Rip currents at beaches, swiftly moving seaward, are potentially dangerous to swimmers, and loss of life from drowning in them probably occurs every summer somewhere in the world. Part of the problem is their counter-intuitive character and also danger alerts are not always very widely spread. Describing and understanding rip currents began around 1940 [1], but the phenomenon is complicated enough that observations leading to further enlightenment are hard to come by.

What is presented here is a possible reason for why these strong currents exist in the first place when another type of nearshore circulation would achieve the same purpose: returning water that is initially brought to shore by incoming waves. The only other logical circulation imagined so far is a two horizontal layer system whereby there is shoreward flow at the surface and seaward flow underneath. Apparently that configuration has never been observed. Why not?

Given the existence of rip currents, many theoretical explanations are available for the various features of an idealized circulation [2], such as the amazing regularity of the spacing between rip currents along straight beaches with uniform bottom topography and constant amplitude waves propagating perpendicularly to the shore.

Two facts are clear: surface gravity waves are always coming into shore and never going back out (except for very steeply sloped beaches and vertical walls), and the waves bring excess mass with them, although there are different opinions about exactly how. In order to conserve mass the excess water must be returned seaward. That is the guiding and demanding requirement. 
All types of waves transport energy, including surface gravity waves, so energy is brought to shore too, but there is no stipulation that energy be conserved in the nearshore region. Also lesser known, and surrounded by some confusion, is the propagation of linear and orbital angular momentum of the fluid particles to the beach, neither of which is conserved either. However, since there is no direct connection between energy, or the linear and angular momenta to rip currents, more discussion of these topics can stop. Only mass conservation is important here.

\section{ARGUMENT}

Maybe the reason why the rip current circulation is the solution to the mass conservation problem in the surf zone, rather than the two-layer system, is that there is less overall friction. Consider the following analogy that could help: thermal convection in a thin layer of fluid heated from below. In this case many (not just two) potential configurations of the flow could all carry out the job of conveying heat upward. Among the regular ones are the triangular, square and hexagonal plan forms. What shows up in most experiments is the hexagonal cells. Recently the hypothesis was put forward that for the hexagons there is the least friction because of the smallest amount of surface area between neighboring cells over which most of the friction occurs at the interaction boundary of the upward and downward streams [3].

Rip currents are narrow and widely spaced. If the schematic diagrams in the references $[1,2]$ are even approximately correct, the spacing to width ratio is significantly greater than 10 to 1 . Aerial photographs would be useful in this regard if they were not so rare. Corroboration comes from one such photo in my possession in the form of a colored postcard of a white sand beach on Maui that clearly shows nine rip currents, white with foam, and the spacing between them in turquoise blue-green.

As few and qualitative as these evidences may appear, a couple of obvious conclusions can be obtained nevertheless. First, the surface area between neighboring rip currents, from shore to where the rip currents dissipate, is much larger than the surface area within each rip current. If a two-layer circulation existed between the excess water brought ashore by the waves at and near the surface and a return flow underneath, there would be friction between these two opposing streams that would extend over a broad horizontal area. Friction associated with the rip current would take place mainly along much smaller vertical surface areas on either side of the outgoing stream. Undoubtedly there will be some friction associated with the longshore currents that feed the rip current, but again these are confined to narrow strips right at the shoreline.

\section{DISCUSSION}

Suppose it turns out that the least friction idea is a correct way to view the rip current circulation. Then the rip current can join a class of geophysical fluid flows that includes three cases in which least friction can actually mean zero friction. For example, in the depth of wave influence it has been proposed that there is no friction connected with a propagating surface gravity wave [4], which leads to an explanation for how such waves have been measured and inferred to travel from an ocean storm to a beach as much as half away around the world.

Also the horizontal dynamics of a tornado produces a velocity structure varying inversely as the radius from the central axis of the storm [5]. There is zero friction for such a velocity function according to the Navier-Stokes equations in polar coordinates. Therefore a reason is provided for how a $200 \mathrm{mph}$ wind can persist for as long as it does.

Thirdly, there is the hurricane where the horizontal dynamics involves the Coriolis force in place of the centrifugal force and produces a rotary velocity that is a constant times the radius from the hurricane's center, the constant being the Coriolis parameter [6]. There again friction is zero.

\section{CONCLUSION}

A hypothetical reason is suggested for nature's solution to the ever present mass flow problem in the 
surf zone, set up by an excess of water brought shoreward by incoming surface gravity waves. Narrow swift rip currents, widely spaced, return the extra mass seaward because there is less friction in such a circulation than in any other one that could accomplish the same job, such as a two-layer system.

\section{CONFLICTS OF INTEREST}

The author declares no conflicts of interest regarding the publication of this paper.

\section{REFERENCES}

1. Shepard, F.P. (1959) The Earth Beneath the Sea. The Johns Hopkins Press, Baltimore, 275 p.

2. Komar, P.D. (1998) Beach Processes and Sedimentation. Prentice-Hall, New Jersey, 336-350.

3. Kenyon, K.E. (2020) Thermal Convection with Least Friction. European International Journal of Science and Technology, 9 (in Press).

4. Kenyon, K.E. (2020) Frictionless Surface Gravity Waves. Natural Science, 12, 199-201. https://doi.org/10.4236/ns.2020.124017

5. Kenyon, K.E. (2020) Tornado's Shear. European Journal of Science and Technology, 9 (in Press).

6. Kenyon, K.E. (2019) Hurricane's Shear. Natural Science, 11, 270-272. https://doi.org/10.4236/ns.2019.119028 